\title{
Química, uma ciência experimental? Aspectos históricos do empirismo racional
}

\section{O empirismo racional de F. Bacon}

\begin{abstract}
A Ciência Moderna reverencia em Francisco BACON (1561-1626) «o maior, mais universal e mais eloquente dos filósofos» ${ }^{1}$ ) pela consagração que ele fez do chamado empirismo racional. No quadro específico deste, o caminho de que dispõem as Ciências da Natureza para decobrir a verdade é a experimentação seguida de indução. No seu domínio, o cientista vive do recurso à observação cuidadosa e à experimentação para se certificar dos factos e para os ordenar o mais perfeitamente possível. Desse recurso nascem as hipóteses que visam explicar os factos observados e sua interconexão; e nele elas se testam, no desejo de se arvorarem em leis de carácter universal. É recorrendo à experiência que as Ciências da Natureza tentam descobrir o que esta esconde e comprovam o que já descobriram, recorrendo, inclusive, a experiências artificiais que de modo algum são contra a Natureza mas em que se «submete esta à tortura" para the arrancar os seus segredos que ela talvez nunca confessasse "voluntariamente" $\left({ }^{2}\right)$. Por isso elas se dizem ciências experimentais.
\end{abstract}

Um século antes de F. Bacon, já Leonardo da Vinci (1452-1519) havia afirmado que «as ciências que não nascem da experiência, ๆ mãe de toda a certeza, são vãs e cheias de erros». Deve notar-se, todavia, que o empirismo que está na base da revolução científica dos séculos XV-XVII é um empirismo racional. E por esta sua característica ele se distingue do experimentalismo que havia sido professado e defendido na Antiguidade (de Alcmeon de Crotona aos helenistas) e na Idade Média (dos árabes a R. Grosseteste ou Rogério Bacon). $\mathrm{O}$ essencial, decisivo e verdadeiramente novo no empirismo que informou a constituição da ciência moderna não é o desenvolvimento do experimentalismo, mas o seu carácter racional, que se traduziu na eclosão da ciência matemática da natureza como requisito que simultaneamente possibilita e torna necessária a experimentação, numa atitude científica em que a teoria é que orienta a observação, suscita a experiência e thes dá um sentido científico.

Foi no quadro do empirismo racional que a Química se tornou uma Ciência autónoma. Que o recurso contínuo à experimentação tem sido a mola real do seu desenvolvimento está igualmente patente na atitude e testemunho de um Vicente Coelho de Seabra (1764-1804), ilustre químico português dos tempos de Lavoisier, como na filosofia subjacente ao chamado Projecto CHEM STUDY $\left({ }^{3}\right)$, nos nossos dias, ecos pontuais da atitude e testemunho de toda uma pléiade de cultores desta ciência.

\section{Vicente Coelho de Seabra:}

«Se reflectirmos sobre a origem dos conhecimentos humanos ainda os mais metafísicos, veremos que todos são devidos à observação e experiência. Mas nenhuma ciência precisa mais deste socorro, do que aquella que trata examinar e conhecer a natureza dos corpos. A chimica he a que toma isto a seu cargo. (...) A experiência pois he o fio Ariádneo com que nos devemos conduzir por entre este labirinto do conhecimento dos corpos» $\left({ }^{4}\right)$.

\section{Projecto CHEM STUDY:}

"As actividades da ciência começam com a observação. A observação é mais útil quando as condições que a afectam são cuidadosamente verificadas. Uma condição é verificada quando é fixa, conhecida e pode ser modificada deliberadamente, se o desejarmos. Esta verificação é obtida da melhor maneira num local especial - num laboratório. Quando a observação é feita debaixo de cuidadosa verificação, dignificamo-la com um nome especial - uma sequência verificada de observações é uma experiência. Toda a ciência se constrói sobre os resultados da experiência" $\left({ }^{5}\right)$.

Não é possivel, porém, falar de idêntica unanimidade de atitude e/ou testemunho quando se trata de definir o entrosamento da experimentação na componente teórica em que se opera a generalização e sistematização das observaç̃̃es factuais. Os defensores do carácter experimental das Ciências da Natureza estão, muitas vezes, em desacordo sobre a natureza do apoio prestado pela experiência à teoria, ou por esta à experimentação. Esse desacordo, particularmente patente entre os fiéis sequazes da lógica indutiva do empirismo racional de F. Bacon e os neopositivistas, também conhecidos pelo nome, à primeira vista um pouco desconcertante, de empiristas lógicos, estende-se ao próprio conceito de experiência e ao carácter paradigmático das teorias.

Nem sempre olhada por uns e por outros, do mesmo ponto de vista, a relação experiência/teoria é para eles objecto de desencontradas posiçð̃es e assunto de calorosos debates. Que estes são questão acesa, contẹmporânea e actual, prova-o, por exemplo, a última conferência orgapizada pela União Internacional para a História e Filosófia da Ciência (IUHPS), realizada em Ghent (Bélgica), de 25 a 30 de Agosto de 1986, toda ela subordinada ao tema Theory and Experiment. Uma breve análise de carácter histórico, ajudará a compreendê-los melhor.

\footnotetext{
* Departamento de Química, Universidade de Coimbra.
} 


\section{Ciência ou Arte?}

Em 1786, Kant negava categoricamente a possibilidade de a química poder alguma vez tornar-se matemática e dedutiva, do que resultaria nunca ela poder ser mais que uma arte engenhosa, e nunca uma ciência verdadeira. Pyrosophia ou philosophia per ignem, ela estaria condenada a simples manuseamento de dados experimentais, estando-lhe vedado filosofar sobre as últimas causas das coisas, distintivo nobre da verdadeira ciência.

Os químicos do século XVIII lutaram arduamente contra este veredicto kantiano que pendia sobre a sua actividade, e tudo fizeram para mostrar à comunidade científica que ela era também uma verdadeira ciência. Defendendo-se, os tratados químicos de então procuram realçar a componente especulativa para que não fossem confundidos com simples "artistas". Mikhail Lomonossow, em 1741, intitula o seu manual de quimica Elementa Chimiae Mathemathicae, fazendo notar, como postulado básico, que o químico verdadeiro deve ser simultaneamente um teórico e um prático $\left({ }^{6}\right)$. Por sua vez, Macquer, em 1749, intitula um seu primeiro tratado de química Éléments de Chymie Theorique, que continuaria, em 1751, com um outro intitulado Éléments de Chymie Pratique. Para ele, só a química teórica que descrevia no primeiro destes seus tratados permitiria «uma representação lógica do básico para o complexo, do conhecido para o desconhecido"; todavia, à química prática competiria ditar a forma dessa representação ( 7 ).

O mesmo Macquer, no seu celebrado Dictionnaire de Chymie de 1778, frisa repetidamente que há nesta ciência uma estreita conexão entre raciocínio e experiência, contrapondo à química experimental uma química raciocinada $\left({ }^{8}\right)$. Outros autores da mesma época falam duma química dogmática e duma química prática ou experimental, duma química racional ou pura e duma química aplicada $\left({ }^{9}\right)$. Vicente Coelho de Seabra, no já citado Discurso Preliminar do seu manual Elementos de Chimica faz outro tanto: «depois de muita meditação, julguei apropósito dividir a chimica em duas partes: theórica e prática: na $1{ }^{a}$ exponho todos os princípios preliminares e toda a theoria (...). Na 2. ${ }^{\mathrm{a}}$ parte, em que trato da chimica prática, classifiquei todos os corpos, que podem entrar no nosso exame» $\left({ }^{10}\right)$.

Nesta reivindicação do estatuto de verdadeira ciência contra o estigma de mera arte que muitos teimavam em impôr aos seus cultores, teoria e prática são entendidas como separação entre uma disposição intelectual e uma actividade manual. Não é, propriamente, a natureza do método que está em causa, mas antes a reivindicação do reconhecimento social do lugar do químico adentro do sistema científico, procurando demonstrar que ser químico era real actividade académica e não simples actividade de laboratório com carácter oficinal.

O próprio título académico que era dado, então, aos professores de química, demonstrador, era indício de certo estigma diferenciador contra que se impunha lutar mostrando que o autêntico químico era simultaneamente um teórico e um prático. Johann C. Zimmerman deu-se mesmo ao trabalho de escrever um manual onde se traçavam as normas que deveriam presidir à educação de um verdadeiro chemicus theoretico-praticus (um químico teórico-prático) em vez de um simples empírico $\left(^{11}\right)$.
Da distinção entre química raciocinada e química prática nasceu a divisão da química em química pura e química aplicada, cunhada, em 1751, pelo químico sueco J.G. Wallerius (1709-1785) no seu tratado Bref om chemiem ratta Beskaffenhet. Neste tratado, a relação entre teoria e prática não é também considerada do ponto de vista da metodologia que deva presidir ao conhecimento químico, mas antes do ponto de vista da utilização possivel do mesmo, ao serviço das necessidades do Homem. A química aplicada, em qualquer das suas áreas (litúrgica, a química das pedras; halúrgia, a química dos sais; telúrgica, a química do fogo; metalúrgica, a química dos metais; hyalúrgica, a quimica do vidro; cromática, a química das cores; etc.) deve guiar-se pela química pura como seu comum «fundamento, norma e conduta" $\left({ }^{12}\right)$.

Com esta divisão que preponderou por completo ao longo de todo o século XIX, adaptando-se bem ao racionalismo filosófico e cientismo iluminista, e que ainda hoje perdura, bem patente, por exemplo no nome da União que superintende internacionalmente em matéria de normas químicas, a IUPAC (International Union of Pure and Applied Chemistry), a terminologia "química prática" caiu quase em desuso. Por sua própria afirmação no "conclave" das ciências, a química deixou de ter necessidade de reivindicar mais o estatuto de ciência. Nem o peso ingente da autoridade filosófica de Kant pôde impedir o total desmoronamento da problemática em termos de ciência ou arte. E deste ponto de vista, deixou de ter qualquer interesse a afirmação do carácter teórico em contraposição ao carácter experimental (e vice-versa) da ciência química.

\section{Experiência vs. Teoria, uma relação de simbiose?}

Dizer que «toda a ciência se contrói sobre os resultados da experiência" $\left({ }^{5}\right)$ é afirmar apenas que a experiência é a base essencial de todo o conhecimento da realidade; não é, de modo algum, pôr de parte, nem sequer subestimar, o valor da teoria. «A teoria proporciona o quadro conceptual que torna a experiência inteligivel. A experiência introduz os teóricos em novos domínios da natureza que por vezes exigem uma revisão da própria concepção da natureza» $\left({ }^{13}\right)$. Envoltos na realidade experimental que os cerca, a qual abrange as chamadas experiências imaginárias, mentais ou ideais $\left({ }^{14}\right)$, os teóricos tentam demonstrar experimentalmente as suas teorias; tanto como expô-las numa linguagem precisa e rigorosa, preocupa-os que elas se confinem estritamente aos dados empiricos. Por sua vez, os experimentalistas tentam formular empiricamente teorias que lhes ofereçam satisfatória sistematização de suas observaçōes.

Define-se assim uma relação de simbiose entre teoria e experiência que o carácter matemático e abstracto da teoria quântica, no primeiro quartel deste nosso século $\mathrm{XX}$, e a metodologia cientifica dos neopositivistas questionam vivamente.

Ernest Mach (1838-1916), um dos criadores do chamado empiriocriticismo, defendeu que aos físicos assiste o direito de usarem ideias e princípios não inferidos necessariamente da experiência; não devem, todavia, perder-se com ideias a que não possa ser dado um significado concreto e preciso através de operações experimentais. Quer dizer, para se manter fiel ao seu estatuto intrínseco de Ciência Experimental, toda e qualquer teoria física que não possa ser provada experimentalmente deve ser abandonada. Positivista convicto, Mach 
defende que a realidade física é definida por operações empíricas reais, não por fantasias da nossa mente $\left({ }^{15}\right)$. A mesma ideia está subjacente ao chamado método postulacional de Einstein em que o cientista parte do mundo da experiência e das experiências para a abstracção de postulados absolutos, num salto conceptual que está muito para além daquilo que qualquer experiência possa verificar, e antes mesmo de possuir qualquer dado que o apoie, somente depois se servindo desses postulados absolutos para deduzir resultados teóricos especificos que possam ser experimentalmente verificados. O salto conceptual em causa é tido como salto intuitivo, uma espécie de suposição inspirada firmada tão somente numa intuição física que transcende a experiência e que, consequentemente, não pode ser deduzida racionalmente a partir desta. No entanto, a sua validade é aferida pela experiência. As leis gerais, a teoria, são válidas na medida mesma em que cumpram o seu objectivo que é a racionalização das experiências. Neste mesmo contexto, Dirac afirmava ser objectivo único da Física Teórica calcular resultados que possam ser comparados com dados experimentais em vista de adequada racionalização $\left({ }^{16}\right)$.

Este mesmo tipo de problemática informa o pensamento do chamado Círculo de Viena formado nos anos que se seguiram à Primeira Guerra Mundial, por um grupo de proeminentes investigadores no domínio da filosofia da ciência, cujo objectivo era promover a aproximação entre a fisolofia e as ciências exactas, numa união duradoura e fecunda $\left({ }^{17}\right)$.

É preocupação básica deste círculo de pensadores a defesa do empirismo científico: todo o conhecimento válido baseia-se, directa ou indirectamente, na experiência. Nesta defesa, preocupa-os muito mais a fundamentação, legitimização e sistematização desse conhecimento do que o modo como a ele se chega, nas mais variadas situaçðes factuais. Muito mais que os factos reais, necessariamente singulares, preocupa-os definir o caminho (a metodologia) que deles leva ao estabelecimento de leis naturais dotadas da maior universalidade possível, meta final verdadeiramente visada por todas as Ciências da Natureza.

Dessa metodologia nos dá conta, por exemplo, a obra The Logic of Scientific Discovery de Karl Popper $\left({ }^{18}\right)$, um dos mais representativos pensadores do Círculo de Viena: o ponto de partida do estabelecimento das leis científicas não são os dados dos sentidos, nem as observaçōes e/ou experiências enquanto tais, mas sim princípios genéricos que às mesmas dizem respeito, que devem ser tomados como sentenças protocolares sobre que deve operar o trabalho cientifico no sentido de as verificar ou falsificar experimentalmente.

As leis naturais enquanto tais não são meramente os resultados observados directamente; generalizando-os, ultrapassam-nos. E não há processo lógico ou matemático que justifique adequadamente o salto de que decorre essa ultrapassagem. Porque é impossivel verificar a universalidade das leis gerais, o procedimento que se impõe como mais lógico será partir dessa mesma universalidade tomada como hipótese de trabalho e tentar infirmá-la por um processo empenhado na sua falsificação. Na medida mesma em que tal universalidade assumida como hipótese resista à falsificação a todo o custo tentada, poderá a hipótese ser tomada como lei geral; só que jamais será possivel saber se uma determinada lei geral foi ou não testada até à exaustão quanto à universalidade! Consequentemente, a ciência será sempre uma ciência em aberto.

Nesta visão, a teoria não depende minimamente da prática, do ponto de vista de necessidade intrínseca, para se estabelecer, mas apenas para se manter. A teoria não precisa da prática para se definir e organizar como sistema, mas tão somente para se solidar, em desejada (e talvez desesperada!) resistência ao tempo. Neste sentido, dizer que a química é uma ciência experimental não é exigir que os conceitos em que se sistematiza sejam elaborados, necessariamente, a partir de factos observados e experiências realizadas; mas tão somente exigir que esses conceitos resistam a toda e qualquer tentativa de falsificação, em si-mesmos e nas suas implicações, por parte de factos e experiências incontestáveis.

Poderemos então concluir com De Broglie: «si tranchée que paraisse à première vue la distinction entre la découverte experimentale et l'invention theorique, une étude plus attentive ne tarde pas a attenuer considerablement, car elle montre que la découverte des faits experimentaux, du moins dans la science actuelle, est a bien des égards une invention tandis que l'invention theorique est en quelque mesure une découverte» $\left({ }^{19}\right)$. Porque o referencial do conhecimento sistemático que a constitui é a experiência, não importa se como fonte em que foi bebido, se como teste em que foi creditado, a Química é uma ciência experimental.

\section{Notas}

(1) - J.R. d'Alembert, Encyclopédie ou Dictionnaire Raisonné des Sciences, des Arls, des Métiers (Lucques, Paris, 1758-1776).

(2) - Este empirismo racional nasceu duma oposiçâo frontal ao dedutivismo aristotélico. Situadas no contexto de tal empirismo, as consideraçōes que constituem o presente trabalho não ignoram que, ao contrário do que muitas vezes se pensa, a atitude aristotélica tem, ainda em nossos dias, ferverosos adeptos. Recorde-se, a titulo de exemplo, a polémica de que se fez eco a revista Nature, em 1937, a propósito de Modern Aristotelianism (Nature, vol. 139, pp. $997-$ -1026), ou entâo as palavras do consagrado cientista que foi $A$. Eddington: unâo há nada em todo o sistema de leis da Fisica que não possa ser deduzido sem qualquer ambiguidade a partir de consideraçōes epistemológicas (...). Uma inteligência familiarizada com o nosso Universo deveria ser capaz de conseguir todo o conhecimento da Física que nós atingimos por experimentaçãon (A Eddington, $R e$ lativity theory of Protons and Electrons, 1936, pg. 327).

(3) - O Projecto CHEM STUDY é um projecto desenvolvido nos anos 60 , nos EUA, por um grupo de cientistas e professores universitários, sob o patrocinio da National Science Foundation, cujo objectivo fundamental era "ver" a natureza da quimica a partir da consideração dos problemas que interessam aos químicos.

(4) - V. Coelho de Seabra, Elementos de Chimica (Real Officina da Universidade, Coimbra, 1788), pg. V.

(5) - G.C. Pimentel, Química uma Ciência Experimental (Fundaçầo Calouste Gulbenkian, Lisboa, 1976), pg. 2.

(6) - M.W. Lomonossow, in Ausgewahlte, vol. I: Elementa Chimiae Mathematicae (Berlim, 1961).

(7) - P.J. Macquer, Éléments de Chymie Theorique (Paris, 1749); id. Éléments de Chymie Pratique (Paris, 1751).

(8) - P.J. Macquer, Dictionnaire de Chymie contenant la théorie et la pratique de cette science (Paris, 1778).

(9) - A. Ridiger, Systematische Anleitung zur reinen und uberhaupl appliscisten allgemeinen chymie (Leipzig, 1756); C.E. Weigel, Einleitung zur allgemeinen scheidekunst (Leipzig, 1788).

(10) - V. Coelho de Seabra, O Cit., pp. X-XI.

(11) - J.C. Zimmermann, Allgemeinen Grundsatze der theoretisch-practischen chemie (Dresden, 1755).

(12) - J.G. Wallerius, Bref om Chemiens ratta Beskaffenhet, Nytta och Warde (Upsala, 1751), pp. 7-28.

(13) - H.R. Pagels, O Código Cósmico, A Física Ouântica como linguagem da Natureza (Ed. Gradiva, Lisboa, 1986), pg. 394.

(14) - Encontra-se já em Galileu um vestigio destas experiências 
mentais - as célebres Gedankenexperimente. A elas recorrem, todavia, com maior consciência e consistência os teóricos da física do nosso século, de Einstein a Heisenberg. Trata-se de experiências que se não podem realizar, por manifestas dificuldades técnicas, das quais se "imagina" o desenvolvimento por recurso a todos os conhecimentos que se possuem do problema, enquadradas num projecto muito preciso e numa discussão que se reveste de toda a seriedade e credibilidade (ver, por exemplo, ref. 18, Apêndice XI, pp. 442 ss., ou A. Koyré, Galileo's Treatise "De motu gravium": the use and abuse of imaginary experiment in Revue d'Histoire des Sciences, 13 (1960), pp. 197-245, reproduzido in Methaphysics and Measurement:
Essays in the Scientific Revolution, Ed. Chapman \& Hall, Londres, 1968 , cp. III).

(15) - H.R. Pagels, O. Cit., pp. 30,66

(16) - Citado in Editor's Outlook, J. Chem. Educ., 8, 209 (1931).

(17) - V. Kraft, The Viena Circle; the origin of neo-positivism (Greenword' Press, London, 1953).

(18) - K.R. Popper, The Logic of Scientific Discovery (Basic Books Inc., New York, 1959).

(19) - Cit, in H. Margeneau, The Nature of Physical Reality - A Philosophy of Modern Physics (McGrawHill Book C.ie, N.Y., 1950) pg. 99.

\section{A regra do octeto}

De acordo com Kossel [1] quando dois elementos se combinam para formar um composto, dá-se uma troca de electrōes de modo que ambos adquirem o número de electrões do gás "inerte" mais próximo. Contudo nem todos os compostos são iónicos, pelo que Lewis veio, quase simultaneamente, a contemplar a formação de compostos covalentes através da partilha de pares de electrões [2]. Esta veio dar origem à regra do octeto, também aplicável aos compostos iónicos. Se bem que Lewis reconhecesse que nem todos os compostos obedecem à regra do octeto, na divulgação da obra isto não foi normalmente tomado em consideração. Actualmente um grande número de livros de Química Geral acentuam a regra do octeto [3-4-5] e discutem, imediatamente a seguir, algumas excepçס̃es. Alguns contrariam o ensino da regra do octeto [6], pelo menos na parte inicial de um curso de Química. Historicamente os gases "inertes" tiveram um papel muito activo na formação deste conceito; não eram reactivos, o que se atribuia à sua configuração electrónica, com o octeto exterior de electrões, $\mathrm{O}$ facto de se saber agora que, de facto, alguns gases raros formam compostos estáveis retira, em parte, uma razão histórica da regra.

O número de excepçð̃es existente, desde os simples $\mathrm{BeCl}_{2}$ e $\mathrm{AlCl}_{3}$ (que se podem explicar razoavelmente) até aos mais complicados $\mathrm{ICl}_{3}$ (com 10 electrões exteriores em volta do átomo central) e $\mathrm{SF}_{6}$ (com 12 electrões), são bastantes, para que a regra do octeto não seja ensinada com grande relevância [7].

A regra do octeto leva-nos a escrever a estrutura do oxigénio incorrectamente, quando o poderíamos escrever como um dirradical, com sete electrões em volta de cada átomo de oxigénio.

Aparecem ainda outros problemas quando se pretende escrever as estruturas de Lewis para $\mathrm{NO}_{3}^{-}$e $\mathrm{NO}_{2}^{-}$, prestando atenção à regra do octeto. Aqui torna-se imperativa a introdução do conceito de ressonância (figura 1)<smiles></smiles>

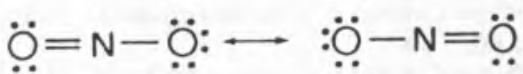

o que não seria necessário no caso de não se prestar atenção àquela regra (figura 2). $\mathrm{O}$ facto destas últimas estruturas não reflectirem o carácter parcial duplo da ligação N-O é de menor importância, dado que o conceito de ligação dupla e simples nem sempre se reflecte na forma de escrever as ligações [8].

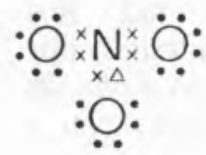

ou<smiles>O=NN(O)O</smiles>

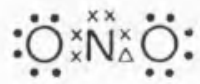

ou<smiles>ONNO</smiles>

Fig. 2

A experiência mostra-nos que a regra do octeto se torna confusa para os alunos, particularmente quando se começa a falar das excepções e dos ajustamentos necessários através da ressonância.

Considera-se que a regra do octeto foi uma regra prática da Química durante algum tempo, mas que é agora desnecessária e confusa para a maior parte dos alunos.

Sugere-se que ela seja mencionada no seu contexto histórico e apenas depois dos alunos terem adquirido alguns conhecimentos mais profundos sobre ligações químicas.

1 - Kossel, W., Ann. Phys. 49, 229 (1916).

2 - Lewis, G.N., J. Amer. Chem. Soc. 38, 762 (1916).

3 - Russel, J.B., Química Geral, McGraw-Hill do Brasil, 1982.

4 - Mahan, B.H., Química - Um Curso Universitário, Edgard Blücher, São Paulo, 1984.

5 - Brescia, F.; Arents, J.; Meislich, H.; Turk, J., Fundamentals of Chemistry, Academic Press, 1980.

6 - McClellan, A.L., Guia do Professor para Química - Uma Ciência Experimental, Fundação Calouste Gulbenkian, Lisboa, 1984. 7 - Snadden, R.B., Education in Chemistry, 81 (1987).

8 - Sandström. J., Endeavour, 37.111 (1984). 